\title{
EVALUATION OF COLLOIDAL SILVER GELATIN SPONGE (GELATAMP) IN PATIENTS RECEIVING ANTICOAGULANT AFTER TOOTH EXTRACTION (CLINICAL STUDY)
}

\author{
Maani $\mathrm{S}^{1}{ }_{B D S}$, Saleh $\mathrm{M}^{2}$ PhD, Melek L ${ }^{3}$ PhD, Sadaka $M^{4}$ PhD
}

\begin{abstract}
: great advantages of both haemostatic and bactericidal effect. without altering the medication dosage. groups.

Results: Adequate socket healing was detected in all patients of both groups. INR) without interruption of their medicine.

Key words: Anticoagulant, Tooth extraction, Gelatamp, Local hemostatic agent, Cardiac patients.

1. B.D.S. Faculty of Dentistry Jordan University of science and technology

2. Professor of Oral \& Maxillofacial Surgery, Faculty of Dentistry, Alexandria University.

3. Lecturer of Oral and Maxillofacial Surgery, Faculty of Dentistry, Alexandria University.

4. Assistant professor of Cardiology, Faculty of Medicine, Alexandria University.
\end{abstract}

Introduction: Patients with a history of heart attack or stroke may take anticoagulant. Because these are anticoagulant medications, bleeding time after dental treatments, may be prolonged. Gelatamp is made of $95 \%$ foam gelatin sponge and 5\% finely dispersed colloidal silver. Gelatamp has the

Objectives: To evaluate clinically the use of Gelatamp to avoid postoperative dry socket and bleeding in patients receiving anticoagulant therapy

Materials and methods: This study was conducted on fifty patients indicated for teeth extraction divided into two equal groups. Study group consisting of 25 patients who received their medicine as usual and extraction was done followed by insertion of gelatamp in the socket and supported with heavy pack. Control group consisting of 25 patients who stopped their medicine until INR reached 1.6 and Prothrombin activity more than $60 \%$ after that extraction was done and the socket was supported with heavy pack. The patients were monitored for 24 hours in both

Conclusion: Gelatamp is an effective material as local hemostatic agent after extraction for anticoagulant patients (within the therapeutic range of

\section{INTRODUCTION}

Many patients taking Coumarin derivatives, such as warfarin, present to the oral and maxillofacial surgeon needing to have teeth extracted. The surgeon is faced with the choice of altering or stopping warfarin and risking thromboembolism or leaving the patient on the warfarin and risking uncontrolled bleeding (1).

The goal of anticoagulant therapy is to prevent clot formation or expansion and Warfarin is the most common drug used in this therapy. Warfarin is an antagonist of vitamin K, an necessary for synthesis of clotting factors II, VII, IX and $\mathrm{X}$, as well as the naturally occurring endogenous anticoagulant proteins $\mathrm{C}$ and $\mathrm{S}(2)$.

Warfarin will affect the factor with the shortest halflife first and the factor with the longest half-life last. The half-lives for factors VII, IX, X, and II are 6, 24, 40, and 60 hours, respective1y Factor VII is affected first, and this increases the prothrombin time (PT). Factors IX, X, and II will be affected later and increase the partial thromboplastin time (PTT) (3).

If warfarin therapy is stopped, it would take about four days for INR to reach 1.5 in almost all patients and with this INR, any surgery can be safely performed (4).

After warfarin therapy is restarted, approximately three days will be needed for the INR to reach 2.0. Therefore, if warfarin is withheld for four days before surgery and treatment is restarted as soon as possible after surgery, patients would have a sub-therapeutic INR for approximately two before surgery, and two days after surgery increasing the risk of thromboembolism (5).

The activity of anticoagulants is expressed using the international normalized ratio (INR). For an individual not taking anticoagulant or antiplatelet drugs, the normal coagulation profile is an INR of 1.0. The INR must be measured prior to dental procedures, ideally this should be done within $24 \mathrm{~h}$ before the procedure (6).

The level of INR suitable for the patient depends on the condition of the patient. The recommended INR level according to the American College of Chest Physicians is between 2.0 and 3.0 for most conditions (7).

The ideal oral surgery hemostatic agent should be safe, well tolerated, bacteriostatic, preformed for operator convenience, packaged, sterile, single-use, remain where applied, dissolve in the first week post surgery. It should also be used in patients taking antithrombotic drugs (8).

Gelatamp (gelatine sponge with colloidal silver); is similar to Gelfoam which is absorbable gelatin sponge available as a sterile sponge like dressing (9). This sponge holds many times its weight in blood and provides a stable scaffold for clot formation, thus, the mode of action of the Gelfoam is believed to be related to formation of a mechanical matrix that facilitates clotting. Gelfoam is thought to act intrinsically by promoting the disintegration 
of platelets causing a subsequent release of thromboplastin, this is in turn simulates the formation of thrombin in the interstices of the sponge. It may be soaked in thrombin or epinephrine solution to enhance its haemostatic properties (10).

Silver is promoted within alternative medicine in the form of colloidal silver, though it has never been proven safe and effective. The silver ion (Ag+) is bioactive and in sufficient concentration readily kills bacteria in vitro. Silver also kills bacteria in external wounds in living tissue and therefore physicians use wound dressings containing silver sulfadiazine (Ag-SD) or silver nano-materials to treat external infections $(11,12)$. Wound dressings containing silver are increasing in importance due to the recent increase of antibiotic-resistant bacteria (13).

Gelatamp is effective against wide range of microrganisms, which are found in the oral cavity. It has been found to be very effective against bacteria, which are resistant to antibiotics. The finely dispersed colloidal silver provides a large active surface for the continuous release of silver ions. As silver does not dissolve easily it is not washed out of the gelatin sponge but is continually released as the sponge is resorbed. This gives Gelatamp a depot antimicrobial effect throughout the resorption process. Gelatamp has the great advantages of both hemostatic and bactericidal effect. It remains in the alveolus and completely resorbed within 4 weeks (14).

The aim of this study was to evaluate clinically the use of Gelatamp to avoid postoperative dry socket and bleeding in patients receiving anticoagulant therapy without altering the medication dosage.

\section{MATERIALS AND METHODS \\ Selection of patients}

This study was conducted on 50 patients who were selected, and operated in the Oral \& Maxillofacial Surgery Department, Faculty of Dentistry, Alexandria University, Egypt. Each patient had been informed about the nature of this study and gave an informed consent.

The patients under anticoagulant therapy (coumarin derived) and indicated for teeth extraction were included in this study. These 50 patients were divided into two equal groups:

1-Study group: Consisted of 25 patients who received their medicine as usual and extraction was done followed by insertion of gelatamp in the socket and supported with heavy pack. The patients were then monitored for 24 hours.

2-Control group: Consisted of 25 patients who stopped their medicine until INR reached 1.6 and Prothrombin activity more than $60 \%$ after that extraction was done and the socket was supported with heavy pack. Suturing was done when needed and the patients were monitored for 24 hours. Warfarin was stropped 5-7 days before extraction and the INR was followed up at the 5th and 7th days when the INR reached $\leq 1.6$, extraction was done. After the procedure, all patients were found to be at low bleeding risk and restarting warfarin was performed immediately.

\section{Inclusion Criteria of selection}

- Patients' age ranged between (25 - 60) years old of both sexes.

- Patient were sent for medical consultation by the physician for assessment of:

○ The International Normalized Ratio (INR values inside therapeutic range $\square 3.0$ ).

○ Bleeding time $(3.75 \pm 1.05$ minutes $)$.

Exclusion criteria of selection

- Patients with liver disease.

- Patients with renal failure.

- Uncontrolled diabetics.

- Heavy smokers.

- Patients with hematological diseases.

\section{Material}

Gelatamp (Gelatamp gelatine sponge with colloidal silver Coltène/Whaledent Ltd. President Suite Kendal House Victoria Way Burgess Hill West Sussex, RH15 9NF/U.K.) is made of foam gelatine and finely dispersed (colloidal) silver. Silver forms silver ions in moist conditions. The porous foam structure absorbs its own weight in blood several times over, promotes thrombocyte aggregation due to the large surface and fills the wound cavity. Gelatamp remains in the alveolus and is completely resorbed within 4 weeks. (Figure 1)

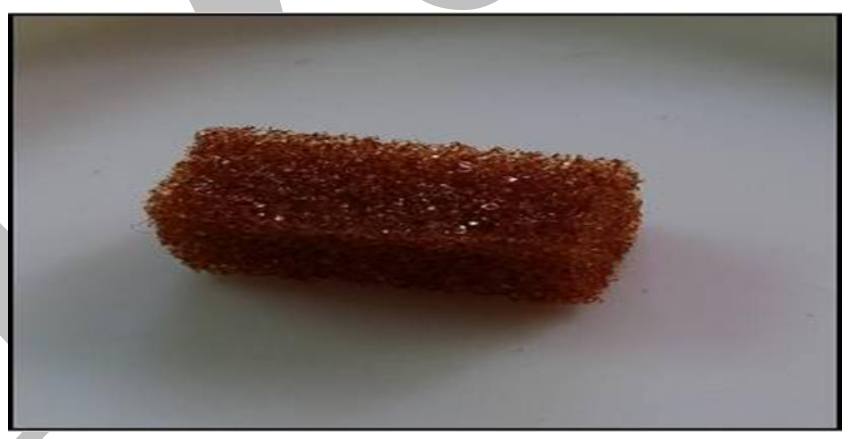

Fig. 1: Showing gelatamp.

\section{Surgical phase \\ Study group}

- Local anesthesia without epinephrine (Mepecaine 3\%, $1.8 \mathrm{ml}$, Alexandria Co. for pharmaceuticals \& Chemical industries Alexandria-Egypt).

- Non surgical extraction of tooth using the appropriate maxillary and mandibular forceps. (Figure 2)

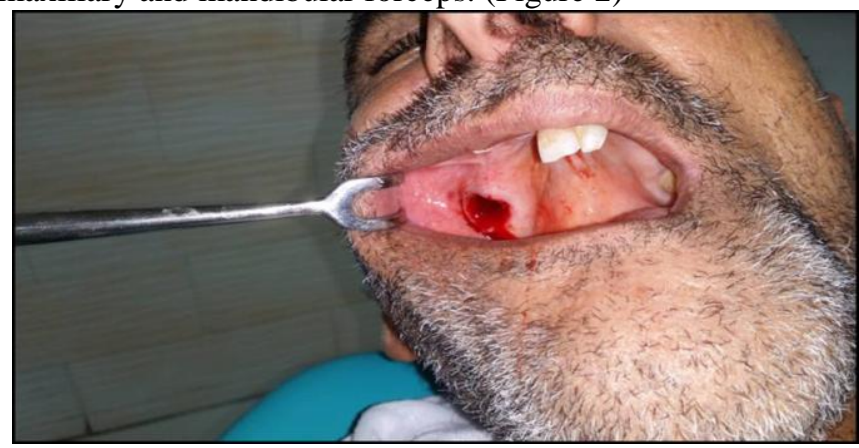

Fig. 2: Socket after tooth extraction. 
The socket was examined for any tooth or bone fragments.

Gelatamp was inserted and supported with heavy pack: it is supplied sterilized and ready for use. The size of the small sponge can be adjusted to fit the wound cavity. Two Gelatamp sponges can be used for larger wounds. Care must be taken that the sponge is not compressed. Pressure on the sponge will destroy its structure and prevent the collection of blood within it. (Figure 3)

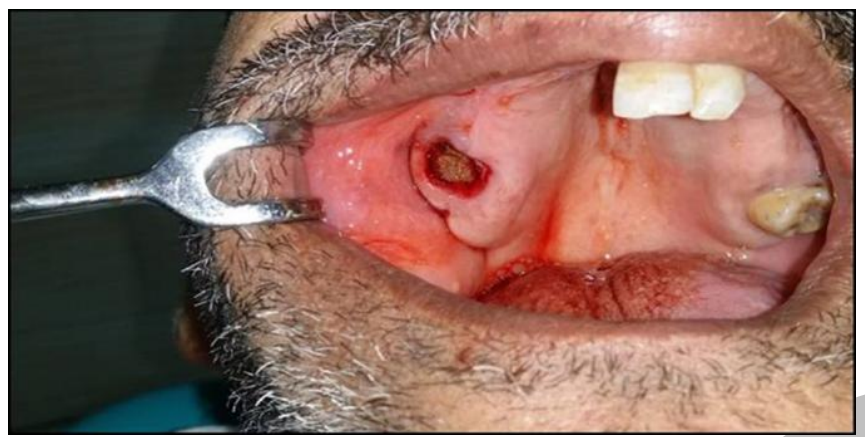

Fig. 3: Showing gelatamp delivery into the socket.

Biting on sterilized gauze to make sure the material in its place.

- Post operative instructions were given to the patient.

\section{Control group}

- Local anesthesia without epinephrine (Mepecaine 3\%, $1.8 \mathrm{ml}$, Alexandria Co. for pharmaceuticals \& Chemical industries Alexandria-Egypt).

- Non surgical extraction of tooth (Figure 4)

- Pack pressure on the socket until bleeding stopped.

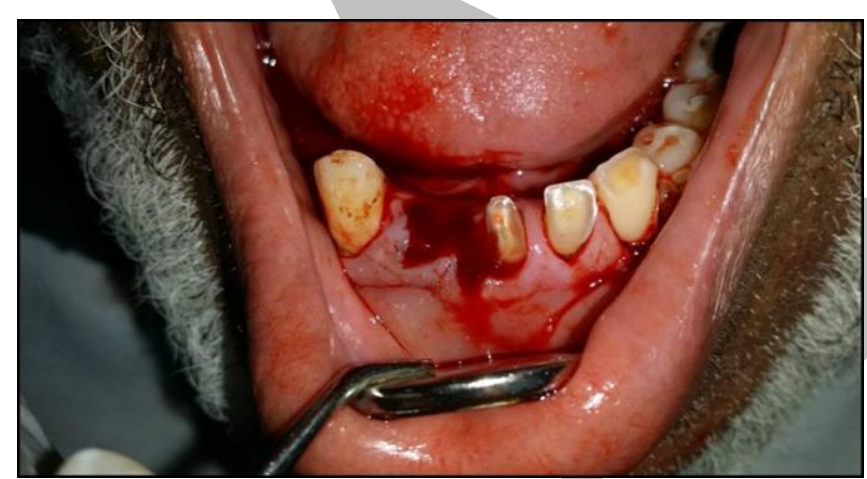

Fig. 4: Showing socket after tooth extracted in the control group.

\section{Postoperative phase}

- It was confirmed that the bleeding was controlled after extraction.

- In case the bleeding did not stop adequately after gelatamp application, suturing was used to approximate the wound margins.

- $\quad$ The patients were under observation over 24 hours.

The postoperative evaluation was done clinically as follows

1) Postoperative bleeding; Hemostasis evaluated immediately after extraction by determining clot formation time by clinical observation.
Bleeding was assessed postoperatively by bleeding scale (15):

Grade 0: Very low (almost no bleeding).

Grade 1: Low (slight oozing of blood from the socket which usually stops by its self or after pressure is applied).

Grade 2: Normal. (Clinically significant).

Grade 3: High. (Bleeding occurs after clot has significantly formed).

Grade 4: Very high (excessive bleeding that could not be controlled by local hemostatic agents or stitches).

2) Postoperative pain:

Pain was evaluated though VAS (visual analogue scale) at first, third and seventh days postoperatively, taking pain scores from 0 to 5.(16) Patients were asked about the pain severity according to (VAS) as follow:

0 No pain

1 Slight pain

2 Mild pain

3 Severe pain

4 Very severe pain

5 Extremely severe pain

3) Postoperative healing:

Adequate socket healing was evaluated clinically at the first and seventh postoperative days including the following parameters:

- Presence or absence of broken down blood clot.

- $\quad$ Presence or absence of sign and symptom of dry socket.

- Presence or absence of inflammation and infection.

\section{Statistical Analysis}

The data were collected and entered into the personal computer. Statistical analysis was done:

- Number and percentage of each group (study group and control group).

- Chi square test and Monte Carlo test used to compare between laboratory investigation of both groups.

- Fisher Exact test for comparing between immediate and each other period.

\section{RESULTS}

In this study, fifty patients (age range of all the fifty patients varied from 30 - 60 years old) were divided equally into 2 groups:

Group 1 (study group) consisting of 25 patients and included 14 males and 11 females.

- Group 2 (control group) consisting of 25 patients and include 16 males and 9 females.

The posterior teeth were the most common teeth extracted. The study group included six maxillary anterior teeth, eight maxillary posterior teeth, four mandibular anterior teeth and seven mandibular posterior teeth. On the other hand, the control group included four maxillary anterior teeth, eight maxillary posterior teeth, three mandibular anterior teeth and ten mandibular posterior teeth. 
The INR in the study group ranged from $1.61-2.00$ in 3 patients, $2.01-2.5$ in 16 patients, $2.51-3$ in 6 patients. In the control group the INR of all the patients ranged from 1-1.6.

The bleeding time was in normal range in the both groups $(3.75 \pm 1.05$ minutes). The Prothrombin activity in study group ranged $20-50 \%$ while in control group ranged from $60-80 \%$.

\section{1) Postoperative Bleeding}

Table 1 shows the comparison between the two groups regarding postoperative bleeding grades at different times:

1- Immediately after tooth extraction before gelatamp was delivered in the study group and before pack pressure was applied in the control group, it was found that there was a significant difference in bleeding between the two groups, with higher bleeding scores detected in the study group.

2- After 5 minutes, 30 minutes, 2 hours, first and seventh day postoperative it was found that there was no significant difference between the two groups.

Table 1: Comparison between the two studied groups according to bleeding

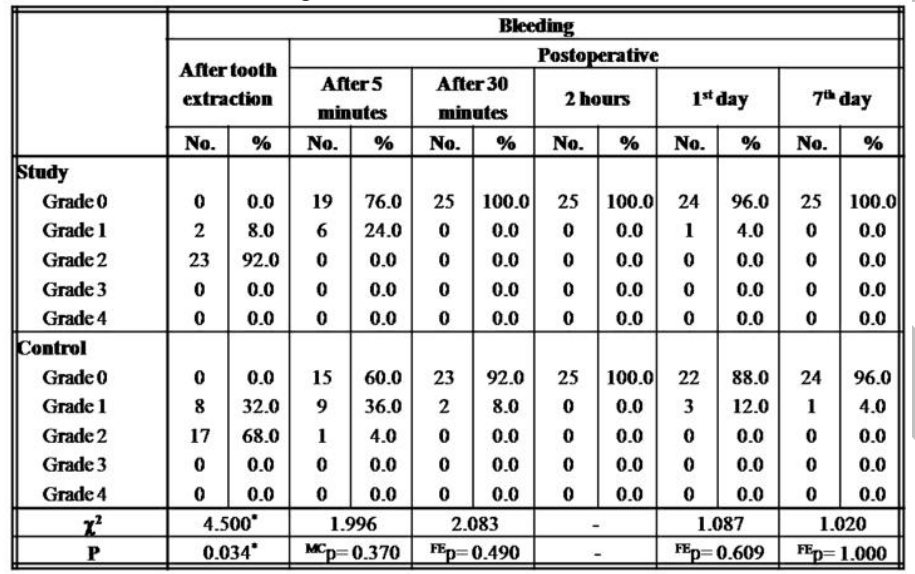

2) Postoperative Pain

Table 2 shows the comparison between the two groups regarding visual analogue scale at different periods of follow up. From this table, it was found that there was no significant difference between the two groups at different times (first, third and seventh days postoperatively).

3) Postoperative Healing on seventh postoperative Day: Adequate socket healing was detected in all patients of both groups without any sign or symptoms of dry socket. (Figures 5,6)

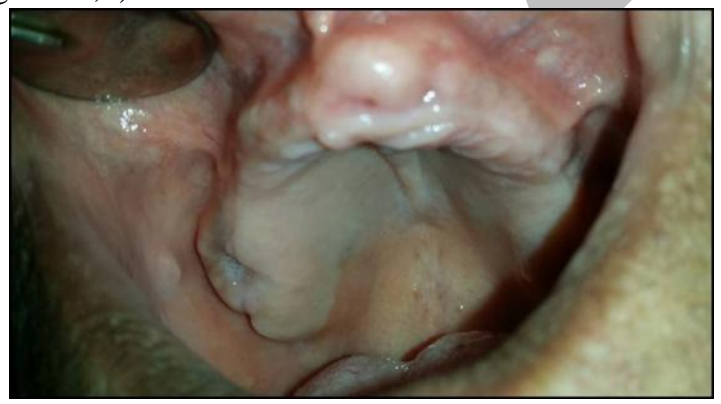

Fig. 5: Showing the healing of socket seventh day postoperative in study group.
Table 2: Comparison between the two studied groups according to pain

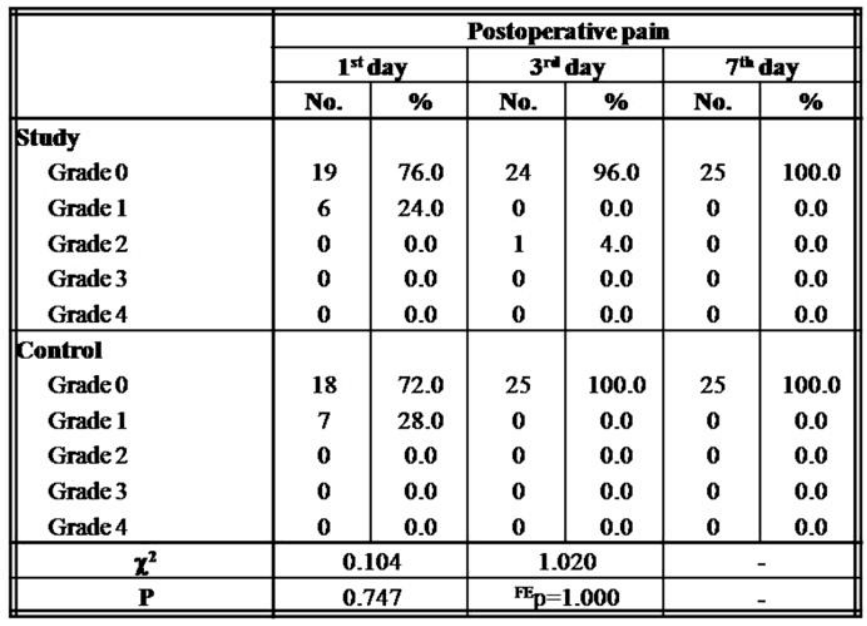

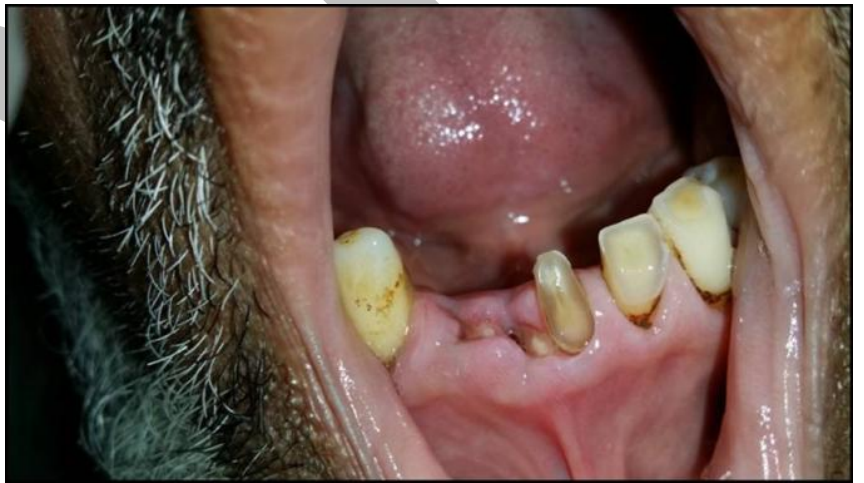

Fig. 6: Showing the healing of socket seventh day postoperative in control group.

\section{DISCUSSION}

In patients who receive oral anticoagulant treatment, dental extractions are a common procedure. In the past, some authors have proposed that the anticoagulant treatment be stopped for several days before the dental extraction (17); others have proposed reducing the dose of anticoagulant intake for several days before extraction (18). In recent years, it has been suggested that extractions be carried out without any interruption or diminution of the anticoagulant treatment but with emphasis on the efficiency of the local hemostasis (19).

In our study the patients were divided equally into two groups. The patients of the first group (study group) were maintained on their medicine and the patients of the second group (control group) stopped their medicine before extraction. Published reports have shown an increase in the number of patients attending dental units worldwide who are on warfarin therapy (20). For many years, controversy has surrounded the correct management of patients on warfarin therapy requiring minor oral surgery (MOS) procedures (21). Over the last two decades, various clinical protocols were suggested for managing such patients, which included withdrawal of warfarin, reducing the dose, substitution of heparin for warfarin, and continuation of the normal dose of warfarin (22). 
Patients treated with oral anti-vitamin $\mathrm{K}$ anticoagulants require periodic monitoring, based on the prothrombin time (PT). Since this parameter is somewhat imprecise, use of the INR (international normalized ratio: proportion between patient PT and control PT, standardized and corrected) is currently advised (23).

In the study group the INR was $\leq 3$. It consisted of 25 patients (14 males and 11 females), in whom gelatamp delivery to the socket was performed to stop bleeding after tooth extraction.

In the control group the INR was $\leq 1.6$ and the prothrombin activity was $>60 \%$. This group consisted of 25 patients (16 males and 9 female) in whom the socket was only supported with heavy pack to stop bleeding after tooth extraction.

Immediately after teeth were extracted we $\leq$ found the bleeding in the study group was higher than in the control group and it was significant because the study group did not stop their medicine so the INR in the study group was higher than in the control group.

Prothrombin time in the study group was higher than in the control group and it was significant, prothrombin activity in the study group was lower than in the control group and it was significant because the level of INR in the study group was higher than in the control group.

Regarding postoperative bleeding after five minutes of tooth extraction and after gelatamp was delivered to the socket in the study group and pack pressure in the control group the result was not significant. However the score of bleeding of patients in the study group was better than that in the control group. After two hours, in both group, no patients had bleeding.

On the first day postoperative, there was one patient in the study group who had bleeding grade 1, while in the control group, 3 patients had bleeding grade 1 . There was no significant difference between the two groups. The four patients said they experienced bleeding after the medicine was taken at night and the bleeding stopped by applying pressure on the socket using wet gauze for 30 minutes.

On the seventh postoperative day, no patients in the study group had bleeding but in the control group, one patient had bleeding grade 1 , the patient said that the bleeding started at night after the anticoagulant was taken. The cardiovascular specialist advised the patient to stop the medicine for 2 days and the bleeding eventually stopped.

In recent years a growing number of investigators have adopted a more conservative approach, preferring not to interfere with drug treatment (i.e., without suspending the medication several days before dental treatment or modifying the dosing scheme), and controlling bleeding after the dental procedure by means of local hemostatic measures (24).

In the present study, results confirm the use of wet gauze with normal saline, gelatamp and suture to control bleeding that is the same as the results obtained by Beirne and Koehler in 1996 (25).

Wahl in 2000 (26), proposed that if INR is in the normal range, there is no need to stop warfarin for dental extraction and if INR is more than the normal range, the dentist should decide on the type of treatment considering the type of dental problem.

Bajkin et al (27) likewise found no significant differences on comparing two groups of approximately 110 patients each (anticoagulation being suspended three days before surgery in one group and maintained in the other).

As indicated by these results, no significant differences were observed in the prevalence of bleeding in one group versus the other - thus supporting the opinion of the above authors that it is not necessary to either suspend or reduce anticoagulation in the context of minor surgery, since local hemostatic measures suffice to minimize bleeding.

In the present study, we evaluated the risk between stopped medicine (risk of thromboembolism) and continuing medicine (risk of bleeding). It has been stated and shown in numerous studies that the risks of arterial and venous thromboembolism can be significantly reduced (by up to $80 \%$ ) by anticoagulation therapy (28).

Regarding the postoperative pain, in the first day postoperative 6 patients in the study group had pain VAS1 and 7 patients in the control group had pain VAS1. On the third day postoperative, one patient in the study group had pain VAS2 and the patient who complained from the pain was found to have a sharp bony edge painful upon touching so it was smoothed and irrigated and the patient presented without pain after 2 days.

The present study showed that from the first to the seventh postoperative day there was no significant difference regarding pain between the two groups as shown in the result. This finding is in match with Malmquist et al (29) who found there was no significant difference in pain between using local hemostatic agent or not after extraction.

In this study, there was no reported incidence of postoperative infection in all patients and the wound healing progressed well in both groups. This is supported by studies which suggested that the level of coagulation and anticoagulation has no significant impact on wound healing after dental extraction (30).

\section{CONCLUSIONS}

From the results of this study we can conclude that:

- Gelatamp is an effective material as local hemostatic agent after extraction for anticoagulant patients without interruption of their medicine (within the therapeutic range of INR).

- There is no need to stop the anticoagulant drug before extraction to reduce the risk of thromboembolism.

\section{CONFLICT OF INTEREST}

The authors declare that they have no conflicts of interest.

\section{REFERENCES}

1. Jaffer AK, Brotman DJ, Chukwumerije N. When patients on warfarin need surgery. Cleve Clin J Med. 2003;70:973-84. 
2. Hirsh J, Dalen J, Anderson DR, Poller L, Bussey H, Ansell J, et al. Oral anticoagulants: mechanism of action, clinical effectiveness, and optimal therapeutic range. Chest. 2001;119:8S-21S.

3. Katzung B. Basic and Clinical Pharmacology. San Mateo, CA: Appleton \& Lange; 1989. p 410.

4. White RH, McKittrick T, Hutchinson R, Twitchell J. Temporary discontinuation of warfarin therapy: changes in the international normalized ratio. Ann Intern Med. 1995;122:40-2.

5. Grip L, Blombäck M, Schulman S. Hypercoagulable state and thromboembolism following warfarin withdrawal in post-myocardial-infarctionpatients. Eur Heart J. 1991;12:1225-33.

6. Evans IL, Sayers MS, Gibbons AJ, Price G, Snooks H, Sugar AW. Can warfarin be continued during dental extraction? Results of a randomized controlled trial. $\mathrm{Br}$ J Oral Maxillofac Surg. 2002;40:248-52.

7. Hirsh J, Fuster V, Ansell J, Halperin JL. American Heart Association/American College of Cardiology foundation guide to warfarin therapy. J Am Coll Cardiol. 2003;41:1633-52.

8. Malmquist JP, Clemens SC, Oien HJ, Wilson SL. Hemostasis of Oral Surgery Wounds With the HemCon Dental Dressing. J Oral Maxillofac Surg. 2008;66:1177-83.

9. Gall RM, Witterick IJ, Shargill NS, Hawke M. Control of bleeding in endoscopic sinus surgery: use of a novel gelatin-based hemostatic agent. J Otolaryngol. 2002;31:271-4.

10. Hassan O, Allah EA, Fouda A. Evaluation of the role of gelatamp in comparison with gelatine sponge on postoperative complications following odontoctomy of impacted mandibular third molar. Dent J. 2011;57:3659.

11. Qin Y. Silver-containing alginate fibres and dressings. Int Wound J. 2005;2:172-6.

12. Hermans MH. Silver-containing dressings and the need for evidence. Am J Nurs. 2006;106:60-8.

13. Chopra I. The increasing use of silver-based products as antimicrobial agents: a useful development or a cause for concern? J Antimicrob Chemother. 2007;59:587-90.

14. Cai YH, Lu CS. A clinical study of gelatamp colloidal silver gelatin sponge on preventing the complication of teeth extraction. Hua Xi Kou Qiang Yi Xue Za Zhi. 2008;26:519-21.

15. Monaco G, Daprile G, Tavernese L, Corinaldesi G, Marchetti C. Mandibular third molar removal in young patients: an evaluation of 2 different flap designs. J Oral Maxillofac Surg. 2009;67:15-21.

16. Pasqualini D, Cocero N, Castella A, Mela L, Bracco P. Primary and secondary closure of the surgical wound after removal of impacted mandibular third molars: a comparative study. Int $\mathrm{J}$ Oral Maxillofac Surg. 2005;34:52-7.

17. Ziffer AM, Scopp IW, Beck J, Berger AR. Profound bleeding after dental extraction during dicumarol therapy. N Engl J Med. 1957;256:351-3.

18. Little JW, Falace DA. Dental management of the medically compromised patient. St Louis: CV Mosby; 1997. pp. 486-8.

19. Blinder D, Ardekian L, Peleg M, Martinowitz U, Taicher S. Oral surgical procedures in patients on anticoagulant therapy. Harefuah. 1996;130:681-3.

20. Aframian DJ, Lalla RV, Pererson DE. Management of dental patients taking common hemostasis altering medications. Oral Surg Oral Med Oral Pathol Oral Radiol Endod. 2007;103:S45.e1-115.

21. Evans IL, Sayers MS, Gibbons AJ, Price G, Snooks H, Sugar AW. Can warfarin be continued during dental extractions? Results of a randomized controlled trial. Br J Oral \& Maxillofac Surg. 2002;40:248-52.

22. Cannon PD, Dharmar VT. Minor oral surgery procedures in patients on oral anticoagulants - a controlled study. Aus Dent J. 2003;48:115-8.

23. Pereira CM, Gasparetto PF, Carneiro DS, Corrêa ME, Souza CA. Tooth extraction in patients on oral anticoagulants: prospective study conducted in 108 brazilian patients. ISRN Dent. 2011;2011:203619.

24. Morimoto Y, Niwa H. On the use of prothrombin complex concentrate in patients with coagulopathy requiring tooth extraction. Oral Med Oral Pathol Oral Radiol Endod. 2010;110:e7-e10.

25. Beirne OR, Koehler JR. Surgical management of patients on warfarin sodium. J Oral Maxillofac Surg. 1996;54:1115-8.

26. Wahl MJ. Myths of dental surgery in patients receiving anticoagulant therapy. J Am Dent Assoc. 2000;131:7781.

27. Bajkin BV, Popovic SL, Selakovic SD. Randomized, Prospective Trial Comparing Bridging Therapy Using Low-Molecular-Weight Heparin With Maintenance of Oral Anticoagulation During Extraction of Teeth. J Oral Maxillofac Surg. 2009;67:990-5.

28. Levine MN, Hirsh J, Gent M, Turpie AG, Weitz J, Ginsberg $\mathrm{J}$, et al. Optimal duration of oral anticoagulant therapy: a randomized trial comparing four weeks with three months of warfarin in patients with proximal deep vein thrombosis. Thromb Haemost. 1995;74:606-11.

29. Malmquist JP, Clemens SC, Oien HJ, Wilson SL. Hemostasis of Oral Surgery Wounds With the HemCon Dental Dressing. J Oral Maxillofac Surg. 2008;66:1177-83.

30. Al-Mubarak S, Al-Ali N, Abou-Rass M, Al-Sohail A, Robert A, Al-Zoman K, et al. Evaluation of dental extractions, suturing and INR on postoperative bleeding of patients maintained on oral anticoagulant therapy. Br Dent J. 2007;203:15. 